\title{
Correction to: Simplified Estimation of Some Main Characteristics of Pores and Constrictions in Granular Materials
}

Feda Seblany, Eric Vincens, and Christophe Picault

\author{
Correction to: \\ Chapter "Simplified Estimation of Some Main Characteristics \\ of Pores and Constrictions in Granular Materials" \\ in: S. Bonelli et al. (Eds.): Internal Erosion in Earthdams, \\ Dikes and Levees, LNCE 17, \\ https://doi.org/10.1007/978-3-319-99423-9_18
}

The original version of the chapter was inadvertently published, missing out some of the figure corrections provided by author in Chapter "Simplified Estimation of Some Main Characteristics of Pores and Constrictions in Granular Materials", which have been now incorporated.

The updated online version of this chapter can be found at https://doi.org/10.1007/978-3-319-99423-9_18 